习习

editorial

ALLAN H. YOUNG

\title{
The Newcastle approach. Invited commentary on ... Are specialised affective disorder services useful? ${ }^{\dagger}$
}

Mood disorders are one of the biggest problems facing medicine today and clearly the single largest challenge in mental healthcare. Mood disorders comprise a diverse grouping of conditions, which range from adjustment disorders to schizoaffective psychosis and from relatively transient to both chronic and highly recurrent conditions. Furthermore, they sit at the very heart of psychiatry, affect every demographic grouping and are frequently comorbid with both physical and psychiatric illnesses. Depression alone is so prevalent in the community that it could potentially overwhelm psychiatric services - in the UK National Health Service (NHS) the vast bulk of these illnesses, by necessity, are managed in primary care. The management of mood disorders in primary care and the optimal relationship between primary care and secondary psychiatric services is very much a matter of current concern, although not the focus of this article. Secondary care services tend to be focused on more complex cases that require more specialised intervention, and employ a range of therapeutic options including both pharmacological and psychological treatment modalities. Within medicine, tertiary and even quaternary services frequently exist for very complex, challenging and rare cases and these units are often centres of excellence for both clinical care and research. However, these specialised services have been perhaps less evident in general psychiatry than in comparable fields.

It is against this background that we must consider the article by the group from Newcastle (Shepherd et al, pp. 41-43, this issue). For many years our conceptual model for severe mental ill-health in the UK has arguably been too focused on schizophrenia. The problems inherent in this approach have been pointed out recently (Goodwin \& Geddes, 2007) and this unbalanced view may have meant that other, more common, disorders may have suffered from a lack of appropriate attention and service development. However, the Newcastle focus on mood disorders has a venerable provenance. The historical roots date from Professor Sir Martin Roth and the current service, initiated by Professor Donald Eccleston, is today benefiting from the able stewardship of Professor Nicol Ferrier and colleagues. Here I must declare a conflict of interest - I worked for over a decade in the Newcastle Regional Affective Disorders (RAD) Unit and remain firmly convinced of the great value of this model of care. Crucially, the 'Newcastle approach' involves not only clinical care which strives to be of the highest order but also cutting-edge clinical and translational research.

Are there lessons that the rest of England (and perhaps even, dare I say it, Scotland, Wales and Northern Ireland) might learn from this article? The first point to note is that there is a clear requirement for such regional affective disorder centres. Within the current fevered climate, where even the role of psychiatry is subject to debate (Craddock et al, 2008), this calm and authoritative article outlining a roadmap for service provision is greatly to be welcomed. Although RAD units belong to the tertiary level of psychiatric services, they should ideally integrate with quaternary or 'supra-regional' services as discussed by Shepherd et al. The authors comment that they cannot provide an international perspective. However, from my viewpoint in North America, there are few models from other countries which have worked so well over a prolonged period of time. An important feature is the integration and partnership with secondary care psychiatry, a feature which is frequently lacking in many other healthcare systems and allows for focused use of the specialist's time within the RAD service. Although the authors point out that other RAD units exist, there are clearly areas of the UK which lack access to such a service. The key challenge is to apply this model to every region served by the NHS so that patients with mood disorders are best treated. This may require an increase in funding and, ideally, well-funded and complementary supra-regional services. Although the case for nationwide RAD units and related services is clear-cut, putting this into effect will no doubt be challenging. Competition from other worthy demands on the NHS' limited resources and the stigma and discrimination which tend to oppose any move towards better funding for mental health services will need to be overcome. Such an effort should nevertheless be made - our patients, their families and society deserve the availability of the highquality services.

\section{References}

CRADDOCK, N., ANTEBI, D., ATTENBURROW, M.-J., et al (2008) Wake-up call for British psychiatry. British Journal of Psychiatry, 193, 6-9.
GOODWIN G. M. \& GEDDES, J. R (2007) What is the heartland of psychiatry? British Journal of Psychiatry, 191, 189-191.
Allan H. Young Professor of Psychiatry, LEEF Chair and Director, Institute of Mental Health, Department of Psychiatry, University of British Columbia, Suite 430, 5950 University Boulevard, Vancouver, BC V6T 1Z3, Canada, email: allan.young@UBC.ca 